\title{
Importância e financiamento público dos laboratórios centrais de saúde pública em ações direcionadas de vigilância sanitária no contexto da Política Nacional de Medicamentos
}

\author{
Jaqueline Kalleian ESERIAN ${ }^{(1)}$ \\ Márcia LOMBARDO(1)
}

${ }^{(1)}$ Instituto Adolfo Lutz, São Paulo, SP, Brasil.

Recebido: 28 jan 2019 Aceito: 10 fev 2019

Autor de

correspondência:

jaqueline.eserian@ial.sp.gov.br

Conflito de interesses:

Os autores declaram não

haver nenhum interesse profissional ou pessoal que possa gerar conflito de interesses em relação a este manuscrito.

\section{Resumo}

A Política Nacional de Medicamentos - PNM, aprovada pela Portaria MS/GM $n^{\circ}$ 3.916/1998 e consolidada na Portaria de Consolidação $n^{\circ} 2$, de 28 de setembro de 2017, Anexo XXVII, é parte essencial da Política Nacional de Saúde, constituindo-se como elemento fundamental para a promoção da melhoria das condições de assistência à saúde pública. Tal política conseguiu implementar uma nova assistência farmacêutica básica, visando o atendimento de necessidades e prioridades de cada local. Desta forma, as três esferas do Governo atuam em parceria de acordo com as diretrizes preconizadas, sendo elas a adoção de uma Relação Nacional de Medicamentos Essenciais, a regulamentação sanitária de medicamentos, a reorientação da assistência farmacêutica, a promoção do uso racional de medicamentos, o desenvolvimento científico e tecnológico, a promoção da produção de medicamentos, a garantia da segurança, eficácia e qualidade dos medicamentos e o desenvolvimento e capacitação de recursos humanos. As diretrizes de regulamentação sanitária de medicamentos e de garantia da segurança, eficácia e qualidade dos medicamentos se complementam e deram impulso à criação da Agência Nacional de Vigilância Sanitária - Anvisa, por meio da Lei no 9.782/1999, que veio a incorporar as funções da Secretaria Nacional de Vigilância Sanitária, criada em 1976. O objetivo deste trabalho foi realizar uma revisão sobre a diretriz da PNM relacionada à garantia da qualidade dos medicamentos, destacando-se a evolução da vigilância sanitária no Brasil e a relevância dos Laboratórios Centrais de Saúde Pública - Lacens. Consultou-se legislação pertinente ao tema por meio do Sistema de Legislação da Saúde (Saúde Legis) e publicações relacionadas, tais como artigos originais, artigos de revisão e guias e informações técnicas contidos em páginas da internet de órgãos oficiais. O Sistema Nacional de Vigilância Sanitária - SNVS foi instituído pela mesma lei que criou a Anvisa (Lei no 9.782/1999). Fazem parte do SNVS, em nível federal, a Anvisa e o Instituto Nacional de Controle de Qualidade em Saúde INCQS. Na esfera estadual, os setores de vigilância sanitária das Secretarias de Estado e seus respectivos Lacens. E em âmbito municipal, os serviços de vigilância sanitária dos municípios. Os Lacens são imprescindíveis para o controle sanitário dos medicamentos, sustentando as ações de vigilância sanitária. Por meio de 
análises fiscais, avaliam a conformidade dos medicamentos distribuídos à população, atuando também na produção de dados científicos e tecnológicos que fortalecem o SNVS. Programas de monitoramento da qualidade são firmados entre os entes do SNVS a fim de verificação da qualidade dos medicamentos utilizados no país. Os dados resultantes dos programas de monitoramento são fonte de informações qualificadas para tomadas de decisão no âmbito da vigilância sanitária. No entanto, é primordial que tais programas estejam alinhados à $\mathrm{PNM}$, no que tange à morbimortalidade da população, priorizandose os medicamentos essenciais distribuídos no Sistema Único de Saúde - SUS. A discussão sobre a descentralização das ações relacionadas à vigilância sanitária iniciou-se em 1998, após a Norma Operacional Básica do SUS 01/96. Os estados contavam apenas com o financiamento próprio, no entanto, a não obrigatoriedade da aplicação na estruturação e funcionamento da área dificultava seu fortalecimento. Em 1999, com a criação da Anvisa e do SNVS, os recursos arrecadados pelo estrato federal foram redistribuídos para os estados, o que valorizou a vigilância sanitária, valendo-se de fonte de financiamento específica para a área. A descentralização das ações de vigilância sanitária ocorreu efetivamente após o repasse dos recursos financeiros para os estados. A gestão descentralizada das ações de vigilância sanitária permitiu sua inserção na agenda de instâncias colegiadas e pactos do SUS. Desta forma, as vigilâncias sanitárias estaduais tiveram condições de se modernizar estruturalmente, qualificar sua equipe técnica e reformular seus processos de trabalho, resultando em maior eficiência do serviço. A Portaria MS/GM n 204/2007 regulamentou o Bloco de Vigilância à Saúde, o qual passou a conter os recursos destinados à vigilância sanitária. A questão de se definir a fonte de financiamento para ações laboratoriais demandou a criação do Fator de Incentivo para Laboratórios Centrais de Saúde Pública - FINLACEN-VISA, que é um incentivo para os Laboratórios de Saúde Pública da Rede Nacional de Laboratórios de Vigilância Sanitária (Portaria MS/GM n³.271/2007). Com a Portaria MS/GM n 1.378/2013, o FINLACEN-VISA passou a compor o Bloco de Financiamento de Vigilância em Saúde. Em 2014, foi publicada a Portaria MS/GM n 475/2014, estabelecendo critérios para o repasse e monitoramento de recursos financeiros federais do Componente da Vigilância Sanitária do Bloco de Financiamento de Vigilância em Saúde, no qual está incluso o FINLACEN-VISA, para os estados, Distrito Federal e municípios. Tais normas relativas ao financiamento e transferência de recursos federais para ações e serviços de saúde do SUS foram consolidadas na Portaria de Consolidação $n^{\circ}$ 6, de 28 de setembro de 2017. Anualmente, são publicadas portarias atualizando os valores de repasse dos recursos financeiros com base na população. A verificação da qualidade dos medicamentos realizada pelos Lacens contribui para ações de proteção à saúde pública e regulação sanitária, consolidando-se como parte essencial do SUS. Considera-se que houve uma grande evolução com relação ao investimento e entendimento da relevância das ações de vigilância sanitária por parte dos órgãos públicos, incluindo-se a criação de um incentivo específico para os Lacens. Ações laboratoriais de vigilância 
sanitária são essenciais para a garantia da qualidade dos medicamentos distribuídos à população, conforme preconizado pela PNM.

Descritores: Política Nacional de Medicamentos; Vigilância Sanitária; Serviços Laboratoriais de Saúde Pública; Financiamento Governamental. 